AperTO - Archivio Istituzionale Open Access dell'Università di Torino

\title{
AIGaN double-walled nanotubes as ammonia gas sensor
}

\section{This is a pre print version of the following article:}

Original Citation:

Availability:

This version is available http://hdl.handle.net/2318/1770355

since 2022-01-19T12:39:16Z

Published version:

DOI:10.1016/j.jssc.2020.121729

Terms of use:

Open Access

Anyone can freely access the full text of works made available as "Open Access". Works made available under a Creative Commons license can be used according to the terms and conditions of said license. Use of all other works requires consent of the right holder (author or publisher) if not exempted from copyright protection by the applicable law. 


\title{
AIN and GaN single-, double-walled and alloy nitride nanotubes as an
}

\section{ammonia gas sensor}

\author{
Naiara L. Marana ${ }^{1}$, Giovanne B. Pinhal ${ }^{1}$, Silvia Casassa ${ }^{2}$, José A. S. Laranjeira ${ }^{1}$, \\ Prescila G. C. Buzolin ${ }^{1}$, Elson Longo ${ }^{3}$, and Julio R. Sambrano ${ }^{1 *}$ \\ ${ }^{1}$ Modeling and Molecular Simulation Group - CDMF, São Paulo State \\ University, UNESP, Bauru, SP, Brazil \\ ${ }^{2}$ Theoretical Group of Chemistry, Chemistry Department I.F.M., Torino University, \\ Torino 10124, Italy \\ ${ }^{3}$ Interdisciplinary Laboratory of Electrochemistry and Ceramics, LIEC - Department of \\ Chemistry, Universidade Federal de São Carlos - UFSCAR, São Carlos, SP, Brazil \\ email:*jr.sambrano@unesp.br
}

\begin{abstract}
The ammonia in the gas phase became a health human problem due to its high toxicity and for causing serious diseases, such as XXX. For this reason, the use of ammonia sensors with high sensibility is necessary for rapid detection and for the necessary measures to be taken on time. In this sense, the nanostructures, in special, nanotubes, can be used as an ammonia sensor, once its size is very reduced and the surface area available to the gas detection is broad. Besides that, the functionalized nanotubes can be modulated to be more sensitive to a specific gas. In this sense, the Density Functional Theory was applied to investigate the aluminum and gallium nitride nanotubes and its alloys to the ammonia detection. The adsorption energies and the changes in the electronic properties were crucial to evaluate the sensibility and interaction between the ammonia molecule and the nanotubes. It was found that ammonia adsorbed preferentially in the external wall nanotube, in the axial-cation. The adsorption energies, bond critical points, and the charge transfers showed that the physisorption occurs and the detection is intense in the AlN nanotubes and on the Al wall in the alloy nanotubes. The detection and sensibility increase in the alloy nanotube, which makes $\mathrm{Ga}_{0.5} \mathrm{Al}_{0.5} \mathrm{~N}$ a great candidate for an ammonia sensor.
\end{abstract}

Keywords: Alloy nanotube; DFT; ammonia; gas sensor. 


\section{Introduction}

\section{OLHAR ARTIGOS DA PASTA BIBLIOGRAFIA}

Diferentes materiais que são sensores de NH3.

Falar de AlN e GaN como sensores de NH3.

Ver se tem algum artigo de heteroestrutura $\mathrm{AlN} / \mathrm{GaN}$ (ou outra) que foi usada ou testada como sensor de NH3 (pq eu pesquisei e não encontrei).

Falar do pq é bom a heteroestrutura e, em especial, nanotubo.

The ammonia $\left(\mathrm{NH}_{3}\right)$ is widely used in many areas, such as food technology, chemical engineering, medical diagnosis, automotive fuels, and others [REF]. For this reason, the atmospheric $\mathrm{NH}_{3}$ is prevenient not only by industry, but also from agriculture, combustion of chemical plants and motors, and by organic materials decomposition [REF]. However, despite being a common atmospheric gas, the $\mathrm{NH}_{3}$ is toxic and it is colorless turns it more dangerous. According to the National Institute for Occupational Safety and Health, $500 \mathrm{ppm}$ of $\mathrm{NH}_{3}$ is dangerous to life and health, and 15 minutes of exposure corresponds to $35 \mathrm{ppm}$ [REF]. In this sense, its detection can be time-consuming, especially in the industry.

Many materials were proposed as an ammonia sensor, however, many times, the sensor does not have a great ammonia sensibility, the cover molecules detection needs to be high for detection to occur, and the device sensor can be wide. LISTAR OS MATERIAIS.

As stated, the chemical bonds formed by the heterostructures significantly change the properties in comparison to that of the original material. In this sense, $\mathrm{Al}_{0.5} \mathrm{Ga}_{0.5} \mathrm{~N}$ and $\mathrm{Ga}_{0.5} \mathrm{Al}_{0.5} \mathrm{~N}$ nanotubes were theoretically analyzed as an ammonia sensor and compared with single- and double-walled AlN and GaN nanotubes. Changes in the band gap, band structure, atomic charges, new levels on the density of states, associate with adsorption energy, were investigated to help to predict the use of the nitride nanotubes as an ammonia gas sensor. Besides, this work also aims to contribute to the advancement in the research of the application of nitride nanotubes, as well as the research of ammonia sensors. 


\section{Computational method}

Periodic computational simulations using Density Functional Theory (DFT) with the B3LYP[1] hybrid functional were made by using the CRYSTAL17 package[2]. The aluminum, gallium, nitrogen, and hydrogen atomic centers were described by 86$21 \mathrm{G}^{*}[3], \quad 86-4111 \mathrm{~d} 41 \mathrm{G}[4], 6-21 \mathrm{G}^{*}[5]$ and 5-11G*[6] all-electron basis sets, respectively. The functional, basis set and accuracy methodology choice are based on the results of previously published research.[7,8]

The following step-by-step strategy has been adopted to simulate $\mathrm{NH}_{3}$ adsorption on nitride nanotubes. The computational nanotube models were defined from a previous study of our group.[7][XXX] First, the nanotubes were obtained from the (0001) surface with one and two layers of AlN (or GaN), of wurtzite bulk structure, and rolled-up to the armchair single-walled (SWNT) and double-walled (DWNT) nanotubes with $20 \AA$ of diameter. These structures were designed as an ideal model to perform adsorption studies thanks to its minimum energy strain. The alloy nanotube models were constructed by the substitution of Ga by Al atom onto the DWAINNT, thus forming $\mathrm{Al}_{0.5} \mathrm{Ga}_{0.5} \mathrm{~N}$ or $\mathrm{Ga}_{0.5} \mathrm{Al}_{0.5} \mathrm{~N}$.

In DFT simulation, in the absence of any dynamic and thermal effects, the final configuration of adsorbate is significantly influenced by its initial position. In order to explore all the possibilities and to individuate the adsorption sites, several different starting configurations were investigated. In this sense, four adsorption sites were considered on the armchair nanotube: the axial and equatorial positions of $\mathrm{Al}(\mathrm{Ga})$ and $\mathrm{N}$ atoms. It is noteworthy that in the alloy nanotubes it was also evaluating the influence of the difference between the internal/external material. For each adsorption site, two different molecular approaches were performed: via nitrogen and the hydrogen atom. Also, it was investigating the adsorption in the cavity of the nanotube.

The adsorption energy was calculated according to the expression: $E a d s=E N T+N H 3-E N T+E N H 3+E B S S E$; where ENT+NH3is the total energy of the optimized nanotube with adsorbed $\mathrm{NH}_{3}$ molecule, ENT is the total energy of the isolated optimized nanotube, ENH3 is the total energy of ammonia in the gas phase, and $E B S S E$ is the correction energy due to the basis set superposition error (BSSE).[9] In this work, the posteriori counterpoise method correction was applied to all the 
energies as EBSSE=ENTfrozen-ENTghost+(ENH3frozen-ENH3ghost); where all the energies refer to the geometries of the two separated parts "frozen" in the minimum adsorption configuration (final optimization structure), with and without ghost functions, respectively.

Finally, the electronic properties of the pure nitride nanotubes and the adsorbed nitride nanotubes were evaluated and compared, which helpt to predict the kind of adsorption and to measure the potential application of the nanotube as ammonia sensor. Also, the $\mathrm{NT}-\mathrm{NH}_{3}$ interactions were characterized by exploiting the potentiality of Bader topological analysis of the electron density, as implemented in the TOPOND program[10] incorporated in the CRYSTAL package. A complete search of the bond critical points (BCP) between the adsorbates and the nanotubes has been carried out, and their topology has been fully characterized to clarify the bonding nature.

\section{Results and Discussion}

The preliminary investigation on the different sites confirmed that $\mathrm{NH}_{3}$ adsorption takes place via nitrogen on the cation in the axial position. Besides, it was found great difference energy into adsorption when occurs in the cavity and the external surface of the nanotubes. The difference found between the adsorption in the inner and

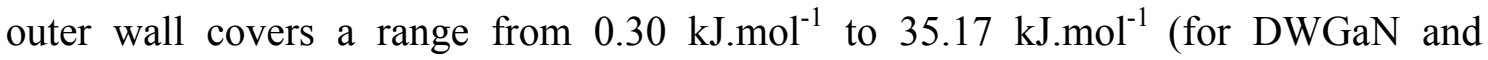
$\mathrm{Ga}_{0.5} \mathrm{Al}_{0.5} \mathrm{~N}$ nanotubes, respectively) and indicates that the lowest energy refers to adsorption on the outer wall of nanotubes (see Figure S1 and Table S1). It was also evaluated the possibility of the ammonia molecule dissociation into $\mathrm{H}$ and $\mathrm{NH}_{2}$, and it was confirmed that in all cases the dissociation did not occur.

Once that the periodic methodology is employed, all the configurations represent the adsorption of an infinite row of $\mathrm{NH}_{3}$ molecule along the nanotube $\mathrm{x}$-direction, which corresponds to $1 \mathrm{NH}_{3}$ per unit cell. However, to measure the influence of the ammonia interaction in the infinite periodic row, the single-molecule dilution limit was evaluated taking to account a supercell calculation and only $1 \mathrm{NH}_{3}$ molecule. It was found that the row of $\mathrm{NH}_{3}$ in the periodic model leads to a stabilization of the $\mathrm{NH}_{3}$ adsorption, and the supercell models have almost $10 \%$ higher energy than the models with 1-row of $\mathrm{NH}_{3}$ molecule. In this sense, only the periodic 1-row $\mathrm{NH}_{3}$ adsorption models were analyzed.

After, the geometry parameters, the distortion, adsorption, and band gap energies were measured tanking to account the minimal adsorption structures discussed before. 
The results are summarized in Table 1 and were compared with the bare nanotubes values.

Table 1: $\mathrm{Al}(\mathrm{Ga})-\mathrm{N}, \mathrm{N}_{\mathrm{NH} 3}-\mathrm{H}$, and $\mathrm{Al}(\mathrm{Ga})-\mathrm{N}_{\mathrm{NH} 3}$ bond lengths $(\AA)$, nanotube $\left(\alpha_{\mathrm{NT}}\right)$ and $\mathrm{NH}_{3}\left(\alpha \mathrm{NH}_{3}\right)$ bond angles (degree), distortion $\left(E_{\text {dist }}\right)$ and adsorption energies $\left(E_{a d s}\right)$ in $\mathrm{kJ} / \mathrm{mol}$ and band gap $\left(E_{\text {gap }}, \mathrm{eV}\right)$ of $\mathrm{NH}_{3} @ \mathrm{NT}$. The sub-index $s$ refers to the atoms of the adsorption site.

\begin{tabular}{|c|c|c|c|c|c|c|c|c|c|c|c|}
\hline Nanotube & $d_{\mathrm{Al}(\mathrm{Ga})-\mathrm{N}}$ & $d_{s(\mathrm{Al}(\mathrm{Ga})-\mathrm{N})}$ & $\boldsymbol{\alpha}_{\mathrm{NT}}$ & $\alpha_{\mathrm{sNT}}$ & $\mathrm{d}_{\mathrm{Al}(\mathrm{Ga})-\mathrm{N}}$ & $d_{\text {NNH3-H }}$ & $\boldsymbol{\alpha}_{\mathrm{NH} 3}$ & $\boldsymbol{E}_{\text {dist }}$ & $E_{a d s}$ & $E_{a d s}+E_{B S S E}$ & $\boldsymbol{E}_{\text {gap }}$ \\
\hline AIN & 1.79 & 1.79 & 120 & 120 & - & - & - & - & - & - & 6.59 \\
\hline GaN & 1.84 & 1.84 & 120 & 120 & - & - & - & - & - & - & 4.73 \\
\hline DWAIN & 1.90 & 1.85 & 116 & 120 & - & - & - & - & - & - & 5.94 \\
\hline DWGaN & 1.98 & 2.15 & 115 & 122 & - & - & - & - & - & - & 3.62 \\
\hline $\mathbf{A l}_{0.5} \mathbf{G a}_{0.5} \mathbf{N}$ & 1.92 & 1.97 & 116 & 122 & - & - & - & - & - & - & 4.28 \\
\hline $\mathbf{G a}_{0.5} \mathbf{A l}_{0.5} \mathbf{N}$ & 1.93 & 2.01 & 116 & 121 & - & - & - & - & - & - & 4.96 \\
\hline $\mathbf{N H}_{3} @ \mathbf{A I N}$ & 1.79 & 1.82 & 120 & 118 & 2.30 & 1.02 & 107 & 2.95 & -18.86 & -5.44 & 4.75 \\
\hline $\mathbf{N H}_{3} @ \mathbf{G a N}$ & 1.86 & 1.91 & 116 & 121 & 2.47 & 1.09 & 107 & 1.23 & -17.78 & -4.64 & 4.61 \\
\hline $\mathbf{N H}_{3} @$ DWAIN & 1.90 & 2.03 & 116 & 121 & 2.24 & 1.02 & 108 & 3.73 & -19.84 & -6.31 & 4.88 \\
\hline NH3@DWGaN & 2.04 & 1.95 & 116 & 122 & 2.40 & 1.02 & 107 & 1.91 & -19.44 & -5.21 & 3.41 \\
\hline $\mathbf{N H}_{3} @ \mathbf{A l}_{0.5} \mathbf{G a}_{0.5} \mathbf{N}$ & 1.92 & 2.00 & 115 & 123 & 2.51 & 1.02 & 107 & 1.34 & -17.64 & -5.46 & 4.14 \\
\hline $\mathrm{NH}_{3} @ \mathbf{G a}_{0.5} \mathbf{A l}_{0.5} \mathbf{N}$ & 1.94 & 2.25 & 115 & 123 & 2.16 & 1.04 & 109 & 35.61 & -22.63 & -7.35 & 4.55 \\
\hline
\end{tabular}

According to Table 01, the nitrogen atom of ammonia interacts with the nanotubes cation in a distance that varies from 2.16 to $2.51 \AA$. In all cases, the ammonia distorts the nanotube structures, the bond distance and angles have a little distortion in the atoms of the adsorption sites. However, the $\mathrm{NH}_{3}$ molecule did not suffer a great distortion in its structure.

It was found a great influence of the BSSE calculated in all the adsorption energies due to the interaction between the $\mathrm{H}$ of ammonia molecule and the nitrogen of the nanotubes. The BSSE energies lead to a decrease of almost $16 \mathrm{~kJ} \mathrm{~mol}^{-1}$ in the adsorption energies and show the importance to evaluate the influence of the basis set superposition in the adsorption calculations using DFT, that if neglected would yield results and incorrect conclusions. With the BSSE correction, the adsorption energies vary from -4.64 to $-7.35 \mathrm{~kJ} . \mathrm{mol}^{-1}$, being the models with minor $E_{a d s}$ the $\mathrm{Al}_{0.5} \mathrm{Ga}_{0.5} \mathrm{~N}$ and DWGaN. Anyway, evaluating the adsorption based only on the adsorption energy, we can say that the adsorption is possible to occur in all the nanotubes analyzed. Nonetheless, to see if occurs the effective adsorption in all models, other analyzes are required. 
The topological analysis of the electron density was performed, in special, to the atoms involved in the $\mathrm{NT}-\mathrm{NH}_{3}$ interaction, the results are reported in Table 2 . The bond critical points (BCPs) found in the Al-N and Ga-N bonds of the nanotubes have, on average, $\rho=0.09, \nabla \rho 2=0.37, H \rho=-0.25$ and $/ V \mid G=1.23$, which suggests a transition character of their bonds, i.e., neither ionic either covalent. In all models, it was found a BCP between the cation of the nanotube and the nitrogen atom of the $\mathrm{NH}_{3}$ molecule, which confirmed the interaction $\mathrm{NTs}_{\mathrm{N}} \mathrm{NH}_{3}$. The analyzes of the BCPs suggest also a transition character of the bond, although the properties showed a tendency to an electrostatic interaction between $\mathrm{NH}_{3}$ and nanotubes. The critical points are closer to the $\mathrm{Al}(\mathrm{Ga})$ atoms, and the charge analyzes of these atoms showed an electronic charge transition from the cation to the nitrogen atom for the $\mathrm{NH}_{3}$ molecules. In contrast, a not appreciable charge transfer is observed between the nanotube atoms, they keep both their volume and charge after the adsorption. No critical point was found between the hydrogens atoms of the $\mathrm{NH}_{3}$ and the nanotube atoms.

As discussed in our previous article [REF], the single and double-walled nanotubes have a negative charge more pronounced around $\mathrm{N}$ atoms in the GaN nanotubes, which corresponding to a greater positive net charge on the Ga atoms than that on $\mathrm{Al}$ atoms. In the alloy nanotubes, the charge flows from $\mathrm{Al}$ to $\mathrm{N}$ direction, the nitrogen atom becomes more negative and the electron density is higher around the Al$\mathrm{N}$ bond. In this sense, it was expected that molecules that tend to withdraw electron density, being adsorbed preferentially in the AlN nanotube or the AlN wall. In fact, the AlN and the $\mathrm{Ga}_{0.5} \mathrm{Al}_{0.5} \mathrm{~N}$ nanotubes showed a better interaction with the $\mathrm{NH}_{3}$ molecules, and have the smaller $E_{a d s}$ and the higher nanotube distortion, due to the interaction. This strong interaction is also confirmed by the greater charge transfer from the $\mathrm{Al}$ atoms of the nanotubes to the $\mathrm{N}$ atom for $\mathrm{NH}_{3}$ molecules.

Table 2: Distance of $\mathrm{Al}(\mathrm{Ga})$ and $\mathrm{N}$ of $\mathrm{NH}_{3}$ atoms to bond critical points ( $\left.\mathrm{d}_{\mathrm{BCP}}, \AA\right)$, and several topological properties electron charge density $(\rho)$, its Laplacian $(\nabla 2 \rho)$, the $|\mathrm{V}| / \mathrm{G}$ ratio, and the bond degree $(\mathrm{H} / \rho(\mathrm{r}))$ and ellipticity $(\varepsilon)$, all in atomic units

\begin{tabular}{cccccccc}
\hline & $\mathbf{d}_{\text {BCP-Al(Ga)s }}$ & $\mathbf{d}_{\text {BCP-N(NH3) }}$ & $\boldsymbol{\rho}$ & $\boldsymbol{\nabla} \boldsymbol{\rho}$ & $|\mathbf{V}| / \mathbf{G}$ & $\mathbf{H} / \boldsymbol{\rho}(\mathbf{r})$ & $\boldsymbol{\varepsilon}$ \\
\hline $\mathbf{N H}_{3} @ \mathbf{a I N}$ & 0.919 & 1.378 & 0.029 & 0.096 & 1.134 & -0.130 & 0.188 \\
$\mathbf{N H}_{3} @ \mathbf{G a N}$ & 0.895 & 1.344 & 0.034 & 0.113 & 1.161 & -0.161 & 0.127 \\
\hline
\end{tabular}




\begin{tabular}{cccccccc}
\hline $\mathbf{N H}_{3} @ D W A I N$ & 1.228 & 1.339 & 0.025 & 0.066 & 1.130 & -0.099 & 0.096 \\
$\mathbf{N H}_{3} @ \mathbf{D W G a N}$ & 1.143 & 1.259 & 0.036 & 0.086 & 1.236 & -0.183 & 0.056 \\
$\mathbf{N H}_{\mathbf{3}} @ \mathbf{A l}_{\mathbf{0 . 5}} \mathbf{G a}_{\mathbf{0 . 5}} \mathbf{N}$ & 1.197 & 1.311 & 0.029 & 0.071 & 1.185 & -0.139 & 0.077 \\
$\mathbf{N H}_{\mathbf{3}} @ \mathbf{G a}_{\mathbf{0 . 5}} \mathbf{A l}_{\mathbf{0 . 5}} \mathbf{N}$ & 0.867 & 1.291 & 0.041 & 0.144 & 1.170 & -0.178 & 0.068 \\
\hline
\end{tabular}

To verify the charge transfer process, the charge distribution on the isodensity surface based on the electronic charge density and the electrostatic potential of nanotubes, focus in the adsorption site, is depicted in Figure 2, with isolines being drawn at increments of $0.001 \mid \mathrm{e} / / \AA$. Comparing with the bare nanotubes, it is seen that in single- and double-walled nanotubes the uniformed charge distribution is altered by the $\mathrm{NH}_{3}$ adsorption. It can be seen the charge transfer between the $\mathrm{Al}(\mathrm{Ga})$ atoms to the $\mathrm{N}$ atom of the $\mathrm{NH}_{3}$ molecule by the positive charge localized at the $\mathrm{Al}(\mathrm{Ga})$ site and the negative charge in the $\mathrm{N}$ atom. A small charge transfer was observed between the hydrogen atom of the $\mathrm{NH}_{3}$ molecule and the nitrogen of the nanotube surface, the hydrogen turns softly more positive by two reasons: the charge transfers for the nitrogen direct bonded $\left(\mathrm{NH}_{3}\right)$ and the transfer for the nitrogen of the nanotube. This behavior is also observed in the alloy nanotubes, however, in the $\mathrm{Ga}_{0.5} \mathrm{Al}_{0.5} \mathrm{~N}$ nanotube, the charge transfer is a little higher. In both alloys, the cation becomes more positive after the adsorption, although in the AlN wall the charge transfer is more effective due to the greater interaction with the $\mathrm{NH}_{3}$ molecules, as observed in the AlN nanotubes.

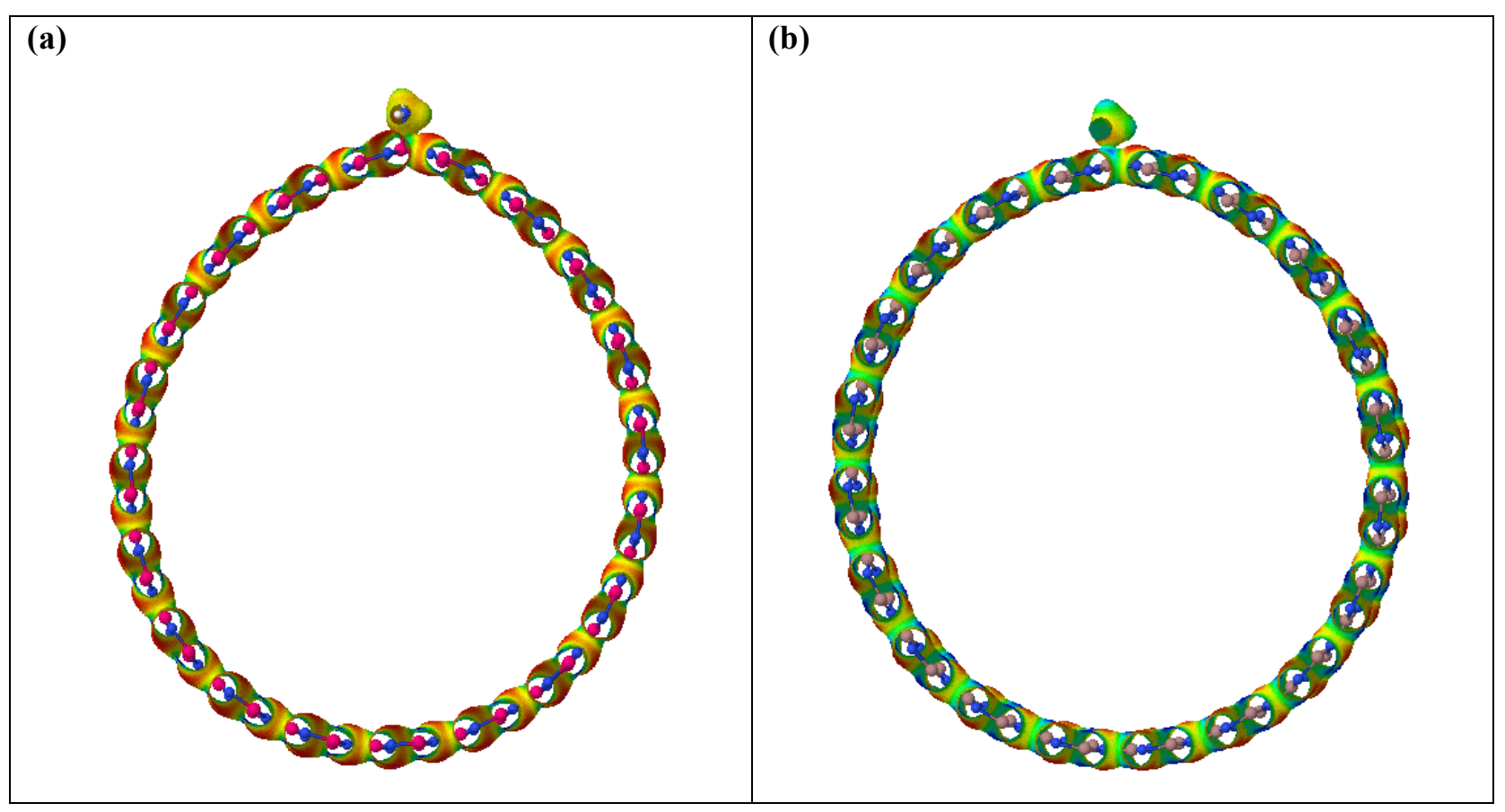




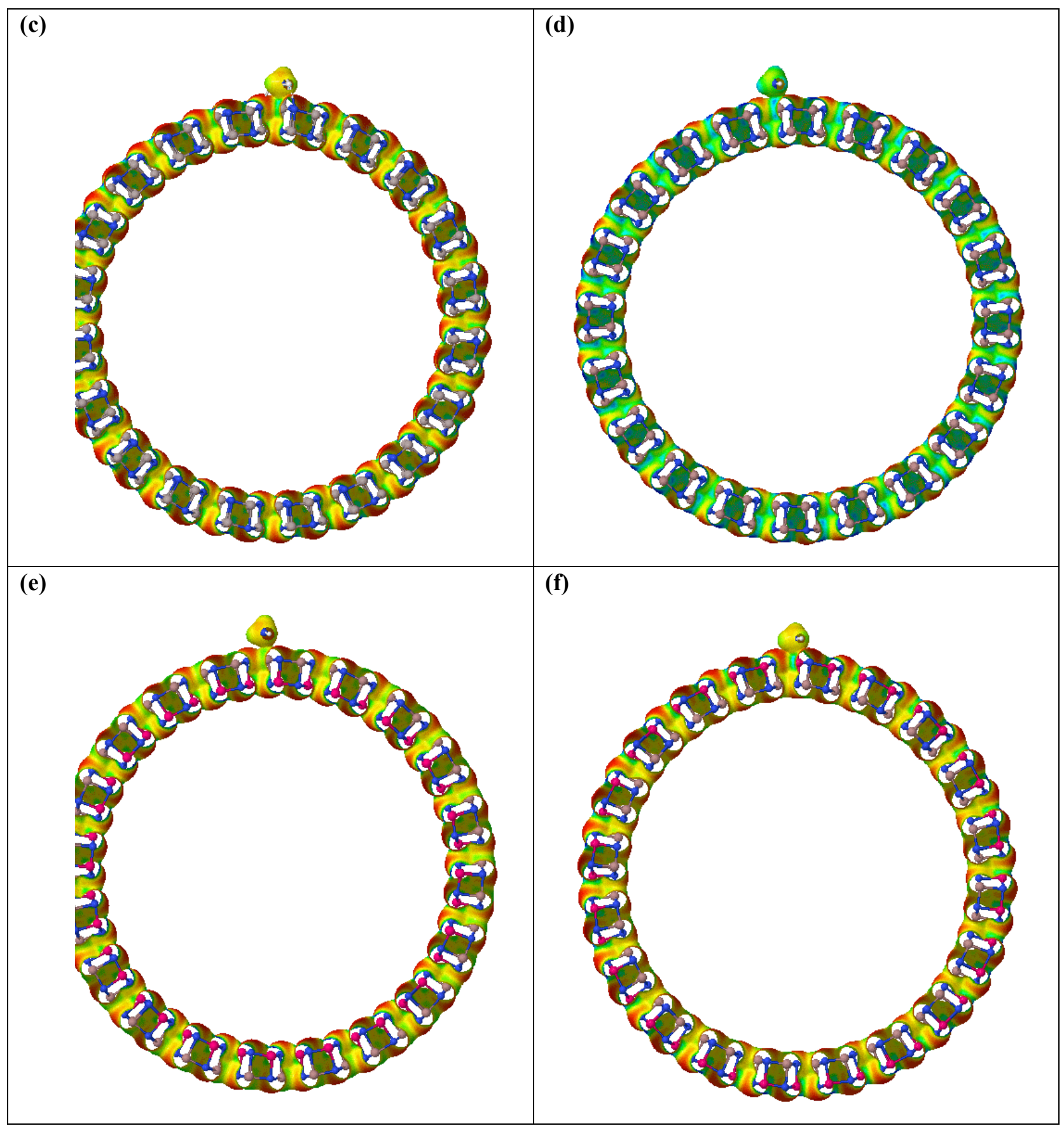

Figure 2: Charge distribution on the isodensity surface of (a) $\mathrm{NH}_{3} @ \mathrm{AlN}$, (b)

NH3@GaN, (c) $\mathrm{NH}_{3} @ D W A L N$, (d) $\mathrm{NH}_{3} @ D W G a N$, (e) $\mathrm{NH}_{3} @ \mathrm{Al}_{0.5} \mathrm{Ga}_{0.5} \mathrm{~N}$ and (f) $\mathrm{NH}_{3} @ \mathrm{Ga}_{0.5} \mathrm{Al}_{0.5} \mathrm{~N}$ nanotubes.

The $\mathrm{NH}_{3}$ adsorption changes the band gap of all systems. However, the AlN nanotubes suffered the highest decrease in their band gaps after the adsorption, $-1.06 \mathrm{eV}$ and -1.84 eV, for $\mathrm{NH}_{3} @ \mathrm{AlN}$ and $\mathrm{NH}_{3} @ \mathrm{DWAlN}$, followed by the $\mathrm{Ga}_{0.5} \mathrm{Al}_{0.5} \mathrm{~N}$, that decrease $-0.37 \mathrm{eV}$. For the other models, the decrease is almost $-0.14 \mathrm{eV}$. The changes in the electronic properties were also observed in the band structures and density of 
states (DOS). Despite the minimum contribution in the DOS (Figure 3) in both valence and conduction bands, the $\mathrm{NH}_{3}$ molecules change substantially the behavior of the nanotubes in the range analyzed, in special, in the band gap region. In a general way, the orbitals of atoms that were the most contributor before the adsorption is maintained after the adsorption. Therefore, the $2 \mathrm{p}$ orbitals of the nitrogen atoms are the most contributor in the valence band and near to the band gap region, while the s orbitals of the gallium and aluminum atoms are the most contributor in the conduction band.

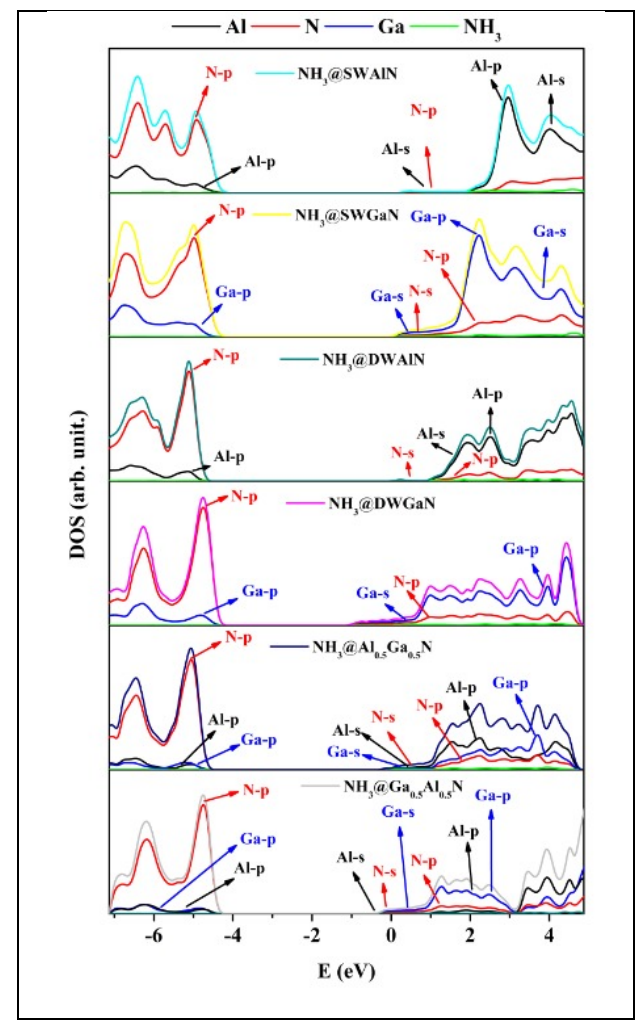

Figure 3: Density of states of $\mathrm{NH}_{3}$ adsorption on analyzed nanotube models (a) SWAIN, (b) SWGaN, (c) DWAIN, (d) DWGaN, (e) $\mathrm{Al}_{0.5} \mathrm{Ga}_{0.5} \mathrm{~N}$ and (f) $\mathrm{Ga}_{0.5} \mathrm{Al}_{0.5} \mathrm{~N}$

\section{Conclusions}

Acknowledgements: This work was supported by the Brazilian Funding Agencies CAPES (grant nos. 8881.068492/2014-01 and 787027/2013) and FAPESP (2016/25500-4 and 2019/08928-9). The computational facilities were supported by 
resources supplied by Molecular Simulations Laboratory, São Paulo State University, Bauru, Brazil.

\section{References}

[1] A.D. Becke, Density functional thermochemistry. 3. The role of the exact exchange, J Chem Phys. 98 (1993) 5648-5652.

[2] R. Dovesi, A. Erba, R. Orlando, C.M. Zicovich-Wilson, B. Civalleri, L. Maschio, M. Rérat, S. Casassa, J. Baima, S. Salustro, B. Kirtman, Quantum-mechanical condensed matter simulations with CRYSTAL, Wiley Interdiscip. Rev. Comput. Mol. Sci. (2018). doi:10.1002/wcms.1360.

[3] B. Montanari, B. Civalleri, C.M. Zicovich-Wilson, R. Dovesi, Influence of the exchange-correlation functional in all-electron calculations of the vibrational frequencies of corundum ( $\alpha-\mathrm{Al}$ 2O3), Int. J. Quantum Chem. (2006). doi:10.1002/qua.20938.

[4] R. Pandey, J.E. Jaffe, N.M. Harrison, Ab initio study of high pressure phase transition in GaN, J. Phys. Chem. Solids. 55 (1994) 1357-1361. doi:10.1016/0022-3697(94)90221-6.

[5] R. Dovesi, M. Causa, R. Orlando, C. Roetti, V.R. Saunders, Ab initio approach to molecular crystals: A periodic Hartree-Fock study of crystalline urea, J. Chem. Phys. 92 (1990) 7402-7411. doi:10.1063/1.458592.

[6] R. Dovesi, C. Ermondi, E. Ferrero, C. Pisani, C. Roetti, Hartree-Fock study of lithium hydride with the use of a polarizable basis set, Phys. Rev. B. (1984). doi:10.1103/PhysRevB.29.3591.

[7] G.B. Pinhal, N.L. Marana, G.S.L. Fabris, J.R. Sambrano, Structural, electronic and mechanical properties of single-walled $\mathrm{AlN}$ and $\mathrm{GaN}$ nanotubes via DFT/B3LYP, Theor. Chem. Acc. (2019). doi:10.1007/s00214-019-2418-1.

[8] N.L. Marana, S.M. Casassa, J.R. Sambrano, Adsorption of NH3with Different Coverages on Single-Walled ZnO Nanotube: DFT and QTAIM Study, J. Phys. Chem. C. 121 (2017) 8109-8119. doi:10.1021/acs.jpcc.6b10396.

[9] F.B. van Duijneveldt, J.G.C.M. va. D. van de Rijdt, J.H. van Lenthe, State of the Art in Counterpoise Theory, Chem. Rev. (1994). doi:10.1021/cr00031a007.

[10] C. Gatti, TOPOND : a program for the application of the quantum theory of atoms in molecules to periodic systems, Acta Crystallogr. Sect. A Found. 
Crystallogr. (2015). doi:10.1107/s0108767396077355.

[11] N.L. Marana, S. Casassa, E. Longo, J.R. Sambrano, Computational simulations of ZnO@GaN and GaN@ZnO core@shell nanotubes, J. Solid State Chem. (2018). doi:10.1016/j.jssc.2018.07.023. 